\title{
Retrato e história. A pintura em Joshua Reynolds
}

\author{
Portrait and History. \\ The Painting in Joshua Reynolds
}

\author{
Luís F. S. Nascimento \\ Universidade Federal de São Carlos (UFSCar)
}

\section{RESUMO}

Célebre pintor do século XVIII, Joshua Reynolds apresentou ao longo dos anos 1769-1790 discursos para Royal Academy of Arts. Neles, expóe uma concepção de pintura que privilegia os quadros históricos. No entanto, o próprio Reynolds pratica a pintura de retratos. Analisar em que medida a feitura de retratos não entra em contradição com o argumento segundo o qual os quadros históricos são aqueles que melhor representam o gênero pictórico é o que se busca problematizar neste texto.

\section{PALAVRAS-CHAVE}

Reynolds; Arte; Pintura; Retrato.

\begin{abstract}
A famous painter of the i8th century, Joshua Reynolds presented throughout the years I769-1790 speeches to the Royal Academy of Arts. In them, he exhibits a conception of painting that privileges historical paintings. However, Reynolds himself practices portrait painting. Analyzing to what extent the making of portraits does not contradict the argument that historical pictures are the ones that best represent the pictorial genre is what we seek to problematize in this text.
\end{abstract}

\section{KEY WORDS}

Reynolds; Art; Painting; Portrait. 
Escrita para ser o primeiro de uma série de quatro tratados sobre as artes plásticas, a Carta sobre o desenho apresenta um panorama da situação das artes na Inglaterra do início do século XVIII. Nela, o seu autor, o filósofo Shaftesbury, mostra-se esperançoso em relação ao futuro das artes em sua terra natal ${ }^{1}$. Embora ainda se refira à pintura como sendo uma arte "vulgar" (Shaftesbury, 2007, p. 175) em seu país, o autor britânico se vê "imbuído de um espírito de profecia" e vislumbra um "gênio ascendente de nossa nação" (Ibid., p. I77). Não obstante o fato de os britânicos não terem, nas palavras de Shaftesbury, "uma planta nativa dessa espécie que seja digna de menção" (Ibid., p. I78), a atmosfera de liberdade que reina entâo aponta para um florescimento das artes. Foi o que teria ocorrido com a música: há algum tempo, no reinado de Carlos II, os músicos britânicos eram dominados pelo gosto francês, mas à medida que "o espírito da naçáo" (Ibid.) tornou-se mais livre, e que se começou a investigar as obras italianas, "conquistamos um gênio muito superior ao deles [franceses] e adquirimos uma escuta e juizo que não devem nada ao que (de melhor) há no mundo" (Ibid.). O mesmo tende a acontecer com as artes plásticas, mas para tanto seria importante um apoio institucional: "Quanto as outras academias, como de pintura, escultura e arquitetura, não há notícias delas. Enquanto isso, o príncipe da nação rival funda instituiçôes, instrui a juventude e oferece pensôes e bolsas no estrangeiro, promovendo o interesse e o crédito de sua nação" (Ibid., p. I82).

Como podemos notar, há uma situação dúbia no que diz respeito às artes na Inglaterra dos anos I7IO, data na qual Shaftesbury escreve sua Carta: se, por um lado, existe a esperança de que surja um gênio local, uma vez que se tem o elemento primordial para esse surgimento (a saber: a liberdade política conquistada graças a um estilo de governo que minimiza a ação real pela do Parlamento); por outro, a Inglaterra está muito atrasada frente à sua grande rival, a França, que, com Luís XIV, já havia instituído academias para formar e promover as artes em seu país. Tal ambiguidade da cena artística em solo inglês é bem descrita por Pedro Paulo Pimenta na abertura de seu livro sobre Shaftesbury:

$\mathrm{Na}$ Inglaterra de Shaftesbury, da chamada Revolução Gloriosa, o triunfo relativo das liberdades civis não foi acompanhado de um proporcional florescimento das artes, contrariando as expectativas daqueles que, a exemplo de nosso autor, se pautam pela tópica tradicionalmente associada ao pensamento de inspiração republicana, que vê uma relação constante entre o estabelecimento de governos livres e o cultivo das artes liberais. (Pimenta, 2007, p. 13)

\footnotetext{
1 O plano de Shaftesbury era o de fazer um conjunto de quatro tratados no qual as artes plásticas seriam o tema principal. Dos textos planejados, apenas dois foram feitos antes da morte do filósofo em 1713: Carta sobre o desenho e Julgamento de Hércules.
} 
O "diagnóstico" (Ibid.) de Shaftesbury combina a condição ainda incipiente das artes na Inglaterra com a esperança de que elas se desenvolvam em alguns anos. Apesar do entusiasmo do filósofo inglês, a Grä-Bretanha ainda esperará algumas décadas até que se veja instituída uma academia. É apenas em I769 que se iniciam as atividades da Royal Academy of Arts, tendo como presidente o pintor Joshua Reynolds. No discurso que profere na abertura da referida academia, em 2 de janeiro de I769, Reynolds se mostra consciente do atraso dos britânicos frente a outros países:

É mesmo difícil dar qualquer outra razão pela qual um império como o da Grá-Bretanha tenha ficado por tanto tempo sem um ornamento táo adequando à sua grandeza, do que o lento progresso das coisas, que naturalmente faz da elegância e do refinamento os últimos efeitos da opulência e poder. (Reynolds, 2002, p. 9)

Elegância e refinamento seriam então o ápice de um processo de contínuo desenvolvimento de um povo ou nação. Assim, o surgimento de uma academia é visto como o cume de um movimento que é, antes de tudo, político e econômico:

Há, neste momento, um número maior de artistas excelentes do que já se soube haver antes em qualquer outro período nesta nação; há um desejo geral em meio aos nossos nobres de se distinguirem como amadores e juízes das artes; há uma superfluidade maior de riqueza entre as pessoas para recompensar os professores, e, acima de tudo, somos patrocinados por um monarca que, sabendo o valor da ciência e da elegância, pensa ser toda merecedora de sua atenção, que tende a suavizar e humanizar a mente. (Ibid., p. II, grifo nosso)

Termo já consagrado pela filosofia, ao menos desde o Ensaio sobre o entendimento humano de Locke, a mente (mind) ganha na letra de Reynolds um lugar de destaque: as artes têm de ser vistas como atividades mentais. Se se exige do candidato a pintor o uso e desenvolvimento de suas faculdades mentais, é também à mente de seu público que a arte se dirige, em um movimento em que a criação da obra e sua recepçáo se complementam: "O valor e a posição de toda arte são proporcionais ao trabalho mental nela empregado ou ao prazer mental por ela produzido" (Ibid., p. 82), escreve Reynolds. Se a pintura é uma arte liberal, se, como afirma o presidente da Royal Academy, não se deve fazer do "êxito mecânico a principal excelência da arte" (Ibid., p. 19), entấo o pintor tem de ser mais do que um exímio mestre das técnicas e seu trabalho tem de ter um conteúdo intelectual. A parte mecânica da pintura é comumente uma "destreza prematura" (Ibid.), a mental só se consegue com estudo e aplicação e, portanto, exige tempo. A "árdua labuta necessária para atingir a exatidão" costuma se chocar com a "impetuosidade da juventude" (Ibid.). Simples rompantes juvenis não podem ser confundidos com genialidade. Aparece aqui a tese segundo 
a qual não há gênio inato, a excelência nas artes é conquistada apenas com trabalho. Reynolds se mostra avesso à opiniáo "falsa e vulgar de serem as regras os grilhóes do gênio" (Ibid., p. I6), e acrescenta: "Elas [as regras] são grilhôes apenas para os homens sem gênio; como a armadura, que no forte é um ornamento e uma defesa, e no fraco e desafortunado torna-se uma carga e aleija o corpo que foi feita para proteger" (Ibid.).

Há, portanto, dois argumentos que se complementam em Reynolds: a natureza mental da arte se alia à constatação de que a maestria é conquistada pela observação de regras. Em outros termos: se não é "ao olho e sim à mente que o pintor de talento deseja se direcionar" (Ibid., p. 75), é com o seu próprio aprimoramento mental que ele adquire a condição de tocar a mente de seu público.

Como então aperfeiçoar a mente de um candidato a pintor? Que regras a ele se apresentam? É neste ponto que uma instituição como uma academia encontra seu valor. Antes de mais nada, Reynolds quer que a Royal Academy seja "um repositório para os grandes exemplos da arte" (Ibid., p. I2). Fazer com que os alunos tomem conhecimento dos clássicos é algo que a academia não poderia deixar de fazer. Além disso, ela também seria responsável por estabelecer uma atmosfera tal que fizesse com que os pupilos náo aprendessem somente com os professores, mas com eles mesmos, pois "acredita-se que um jovem recebe instrução mais facilmente de seus companheiros, cujas mentes estão aproximadamente no mesmo nível da dele, do que das que lhe são muito superiores; e é de seus pares apenas que vem o fogo da emulação" (Ibid., p. I4). O contato direto entre alunos promove o desenvolvimento da arte na medida em que propícia a saudável competição entre eles. A academia também pode fazer com que os estudantes entrem em contato com princípios próprios da pintura que, sozinhos, demorariam muito para aprender. Por fim, ela seria responsável pela promoção de uma disposição adequada ao exercício da pintura, a saber: a de preparar a mente para apreender e colecionar situaçóes, imagens ou materiais que podem vir a ser de grande importância para a execução de uma obra no futuro. Reynolds aqui nos dá o exemplo do general Filoponemo, que se acostumou a pensar em situaçóes de guerra mesmo em períodos de paz, de modo a ter um repertório de estratégias e soluçóes ao qual poderia recorrer quando estivesse em batalha. Esse método, acrescenta o pintor inglês, fazia com que o general estivesse sempre pronto para todas as possíveis ocasiōes de guerra e "nada poderia acontecer que já não tivesse se acostumado a considerar" (Reynolds, 2002, p. 5I). Como Filoponemo, o pintor deve ter "uma mente sempre absorta em sua profissão", levando em consideração os temas que comumente surgem na história da arte: "Deve haver alguma coisa na ação, ou no objeto, que interesse universalmente aos homens e 
atinja poderosamente a simpatia pública." (Ibid., p. 83) Daí a importância do conhecimento das letras clássicas e das Escrituras, cujo "curso corrente de leitura tornaram familiares e interessantes a toda Europa" (Ibid., p. 84).

$\mathrm{O}$ fato de serem universalmente conhecidos faz com que os mitos e poemas gregos e romanos, assim como as histórias bíblicas, sejam tomados como aqueles temas que melhor se aplicam à arte pictórica. Embora Reynolds admita que cada gênero de pintura tem sua excelência, é a pintura histórica que ele identifica como sendo a superior, aquela na qual o pintor mostra sua maestria. Ao ler ou escutar uma história, "todo homem forma uma pintura em sua mente da ação e expressão das pessoas envolvidas. $\mathrm{O}$ poder de representar essa pintura mental na tela é o que chamamos de invenção em um pintor" (Ibid.). Mais uma vez nos vemos diante do argumento segundo o qual o pintor náo cria a partir de nada, e que sua arte demanda o estudo minucioso da poesia, da prosa consagradas e de outros mestres pintores. O que dizer então da opiniáo corrente que afirma que a pintura tem na natureza o seu modelo principal? Reynolds nos responde: "A minha noção de natureza compreende náo só formas que a natureza produz, mas também a natureza ou fábrica internas e a organização, se posso assim chamar, da mente e imaginação humanas" (Ibid., p. 2I2).

A natureza não é apenas o que os sentidos nos fornecem. Da imediatez sensível o artista tem de abstrair o que nela é particularidade e extrair daí uma noçáo ideal ou geral com a qual irá trabalhar. Náo é então copiando servilmente a natureza que se atinge a perfeição em pintura. Os objetos particulares sempre apresentam imperfeiçóes e a beleza conquista sua naturalidade por meio de uma atividade mental: "Em suma, o que quer que agrade tem em si o que é análogo à mente e é, portanto, no mais elevado e melhor sentido da palavra, natural." (Ibid., p. 219)

O estudo de mestres como Rafael e Michelangelo pode nos ensinar melhor acerca da beleza natural do que a mera observação dos objetos. Daí a necessidade de imitálos, "de segui-los parcialmente, parodiá-los, mudar a função de uma figura enquanto se retém a atitude, inverter o significado de um gesto dado", como escreve Edgar Wind em um ensaio que tem Reynolds e Blake como tema (Wind, I986a, p. 83). O próprio Reynolds praticou esse tipo de empréstimo ao pintar, por exemplo, uma paródia da Escola de Atenas de Rafael ou ao colocar o célebre ator Garrick entre a comédia e a tragédia, em uma postura que nos reenvia à clássica imagem de Hércules na encruzilhada. Referências à história da arte não só são admissíveis como são aconselháveis quando se pretende fazer uma pintura histórica, que também poderia ser "chamada de poética" (Reynolds, 2002, p. 89), diz-nos Reynolds.

Embora a regra que afirma que temos de encontrar figuras ou histórias difundidas para arte se aplique melhor à pintura histórica, ela também teria de valer para todos os outros gêneros pictóricos, até mesmo para aquele que parece mais se afastar 
de generalizaçóes e abstraçóes: o retrato. A esse respeito, escreve nosso pintor: "Mesmo em retrato, a graça e, podemos acrescentar, a semelhança consistem mais em considerar o ar geral do que em observar a similitude exata de cada traço." (Ibid., p. 86, grifo nosso)

Como se sabe, Reynolds foi um grande retratista. Fez também autorretratos, sem deixar de afirmar que o pintor "aprende a desenhar de verdade quando náo copia nenhum objeto em particular" (Ibid., p. 62). Deste modo, a destreza do grande retratista estaria justamente na capacidade de expor algo que vai além das meras particularidades: o que ficaria na mente do espectador é o elemento universal da pintura, o que dela resta não são detalhes da roupa ou da luz em que aparece o retratado, mas isso que Reynolds, na passagem acima citada, chamou de ar geral. Como gênero inferior ao histórico, o retrato sempre está preso às suas limitações. "Um pintor de história pinta o homem em geral; um pintor de retratos, um homem particular e, consequentemente, um modelo defeituoso" (Ibid., p. II2), escreve o presidente da Royal Academy. Nesse sentido, o bom retrato é aquele que se aproxima dos grandes temas da pintura histórica ao buscar abstrair de seu modelo tudo o que nele é particular:

Náo posso deixar de mencionar aqui uma circunstância na pintura de retratos que talvez ajude a confirmar o que tem sido dito. Quando um retrato é pintado no estilo de história, não sendo uma representação exata e pormenorizada de um indivíduo, nem completamente ideal, todas as circunstâncias devem corresponder a essa mistura. (Ibid., p. I46)

Resta ao retratista encontrar esse meio-termo e fazer de sua pintura algo que vai além do que no retratado é particularidade. O próprio trabalho de Reynolds parece encontrar essa medida quando, por exemplo, faz dos retratos que pinta imagens consagradas pela literatura e pelas artes, como é o caso de Mrs Stanhope como melancolia, Mrs Stanhope como contemplação, Elisabeth, duquesa de Manchester como Diana com seu filho George, visconde Mandeville como cupido, ou mesmo quando se autorretrata ao lado do busto de Michelangelo. Sem deixar de ser retratos, esses quadros nos levam à consideração de elementos que não se prendem às particularidades dos retratados e ascendem a uma condiçáo superior, aproximando essas imagens àquelas que figuram em uma pintura histórica. Desse ponto de vista, o Reynolds que vemos ao lado do busto de seu mestre (Michelangelo) já não é mais um pintor em especial e se aproxima da imagem do pintor, em geral. Em favor desse argumento de Reynolds, poderíamos pensar nos retratos cujos modelos não são desconhecidos. Se ainda os admiramos, não é mais pela provável semelhança com os seus traços naturais, mas por aquilo que, no quadro, é a excelência da pintura seu caráter mental. 
Criticado pelo ensaísta William Hazlitt, que vê em seus textos certas contradiçóes e que não aceita a tese da generalização e abstração das particularidades, chamado de "tolo, mentiroso, hipócrita, patife" ${ }^{2}$ por um William Blake que nele reconhece a imagem opressora das regras que tolhem o gênio criativo, a verdade é que Reynolds, por bem ou por mal, consegue realizar o que na época de Shaftesbury era apenas um projeto: o estabelecimento de uma instituição ${ }^{3}$ que pudesse promover e cultivar questôes que ajudariam no implemento da pintura e na formação do gosto de sua pátria. Dirigindo-se ao público da Royal Academy, ele reitera seu compromisso com uma concepção de arte pautada pela mente e pela razão: "Formar esse gosto justo sem dúvida está em seu poder, mas é à razão e à filosofia que os senhores devem recorrer; delas os senhores devem tomar emprestado a balança pela qual será emprestado e estimado o valor de toda pretensão que se introduz no que os senhores notam" (Reynolds, 2002, p. 252).

\section{Referências bibliográficas}

Hazlitt, W. (1983). “On certain inconsistencies in Joshua Reynolds's Discourses”. In: Table talk, or, original essays. Nova York: Chelsea house.

Locke, J. (20II). An Essay concerning Human Understanding. Oxford: Clarendon Press.

Pimenta, P. P. (2007). A linguagem das formas. Sáo Paulo: Alameda.

Reynolds, J. (2002). Tradução comentada de Discourses on Art de Sir Joshua Reynolds. Tradução de Jussara Zottmann Abrahão. Dissertação de mestrado apresentada ao Departamento de Filosofia - USP: São Paulo.

Reynolds, J. (1992). Discourses. Londres: Penguin books.

Shaftesbury. (2007). "Carta sobre a arte ou, ciência do Desenho". In: Pimenta, P. P. A linguagem das formas. São Paulo: Alameda.

Shaftesbury. (200I). "A letter concerning design". In: Anthony Ashley Cooper, the Third Earl of Shaftesbury Standard Edition. Aesthetics, I, 5, Stuttgard: Frommann-Holzboog.

Shaftesbury. (200I). "Plastick, or the original, power and progress of designatory art". In: Anthony Ashley Cooper, the Third Earl of Shaftesbury Standard Edition. Aesthetics, I, 5, Stuttgard: Frommann-Holzboog.

Wind, E. (1986a). "Blake and Reynolds". In: Hume and the Heroic Portrait. Oxford: Clarendon Press.

\footnotetext{
2 Vide Wind, i986a, p.8I.

3 "Seu papel (da Royal Academy of Arts) ficou sendo o de um órgão oficial, definidor de padróes, destinado a treinar profissionais e a realizar exposiçóes" (Abrahão, J. Z. "Introduçáo". In: Reynolds, 2002, p. iv).
} 
Wind, E. (1986b). "A Source for Reynolds's Parody of School of Athens”. In: Hume and the Heroic Portrait. Oxford: Clarendon Press.

Wind, E. (1986c). "The Maenad under the Cross. Comments on an Observation by Reynolds". In: Hume and the Heroic Portrait. Oxford: Clarendon Press.

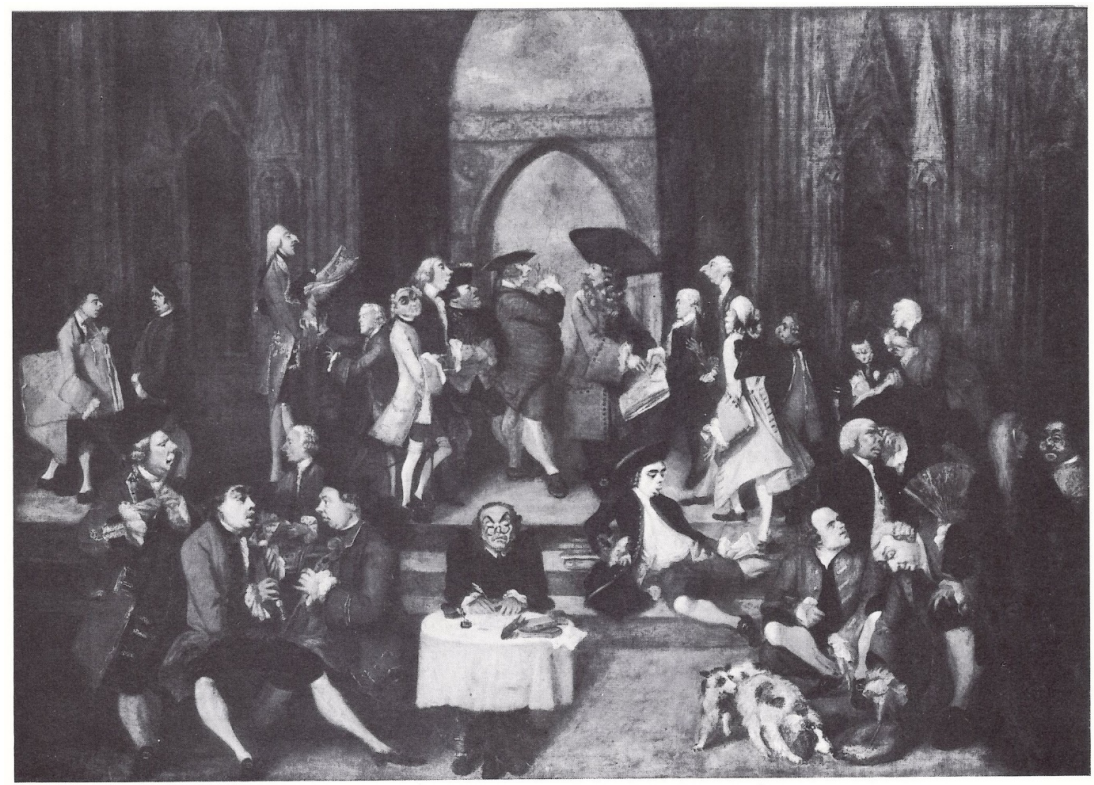

Reynolds: Parody of Raphael's 'School of Athens'. Caricatures of English Visitors to Rome.

Dublin, The National Gallery of Ireland.

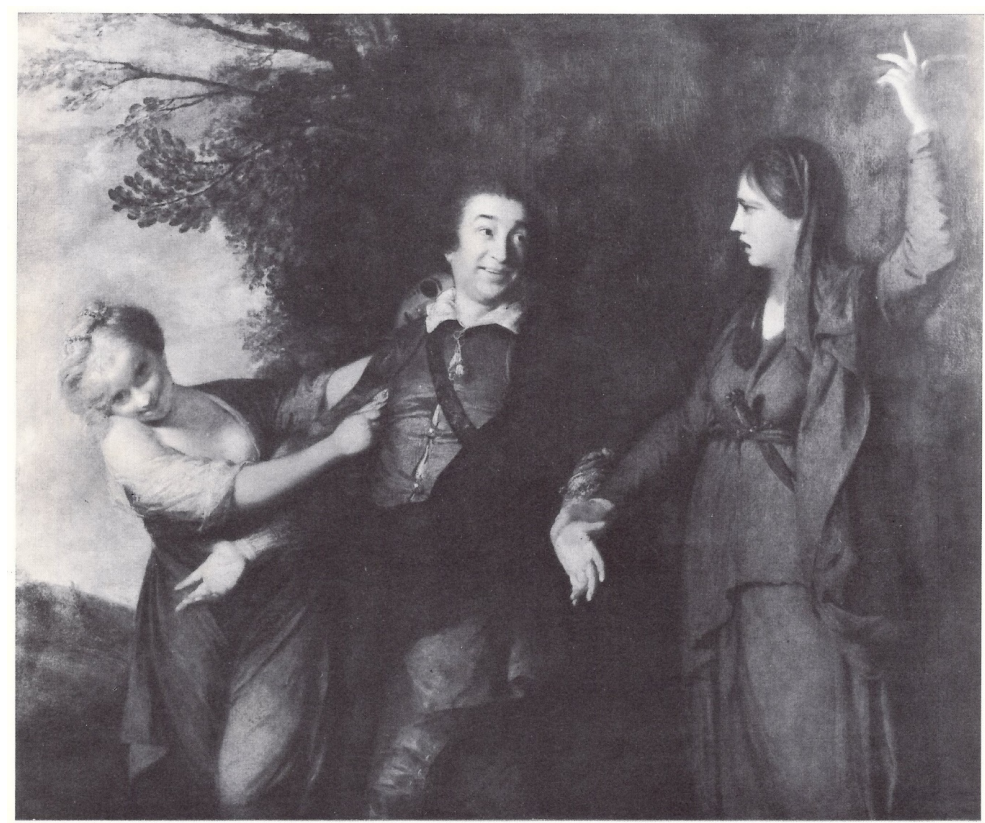

Reynolds: Garrick between Tragedy and Comedy. Private Collection 


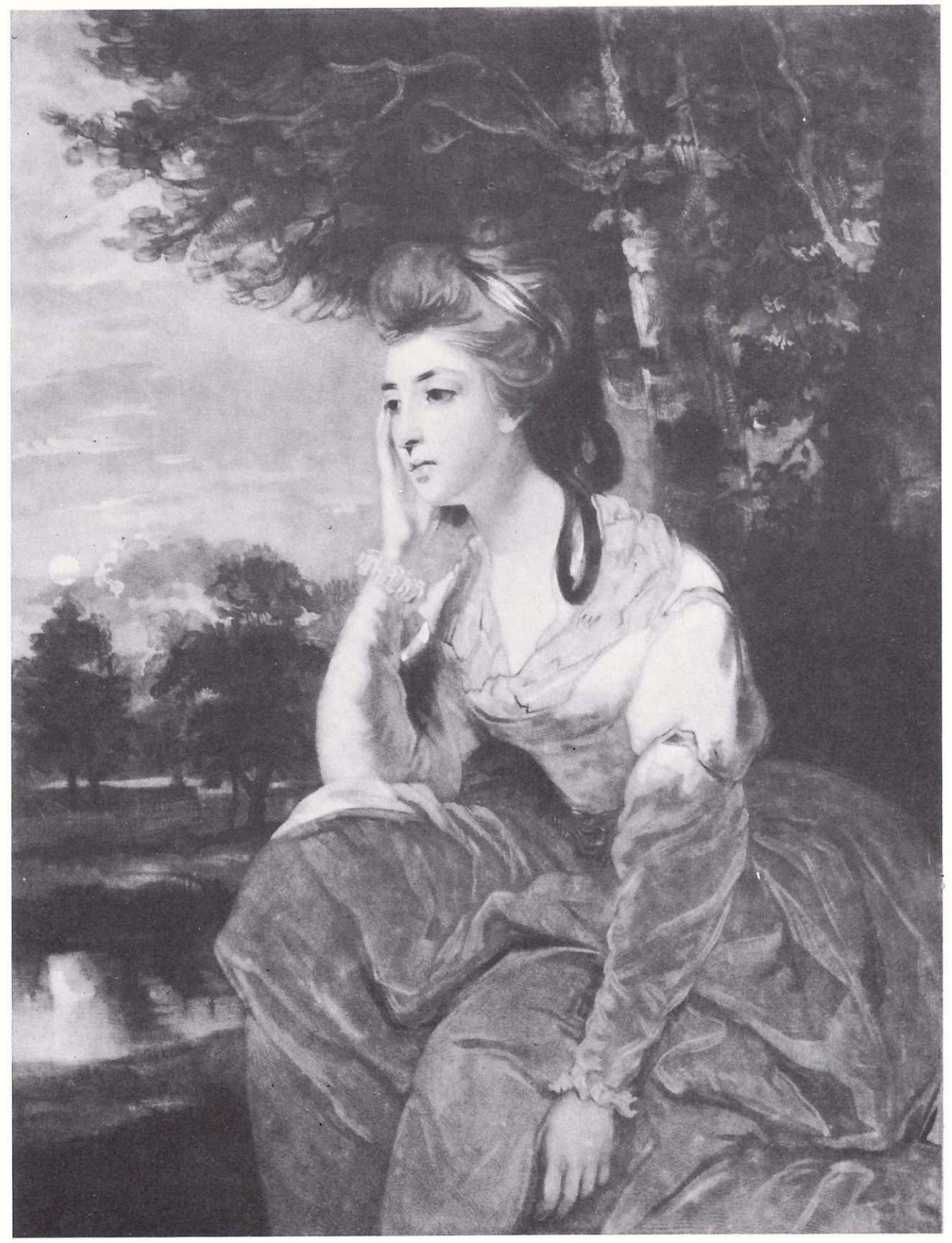

Reynolds: The Hon. Mrs Stanhope (or Spencer?) as Melancholy. Mezzotint by J. R. Smith. London, British Museum 


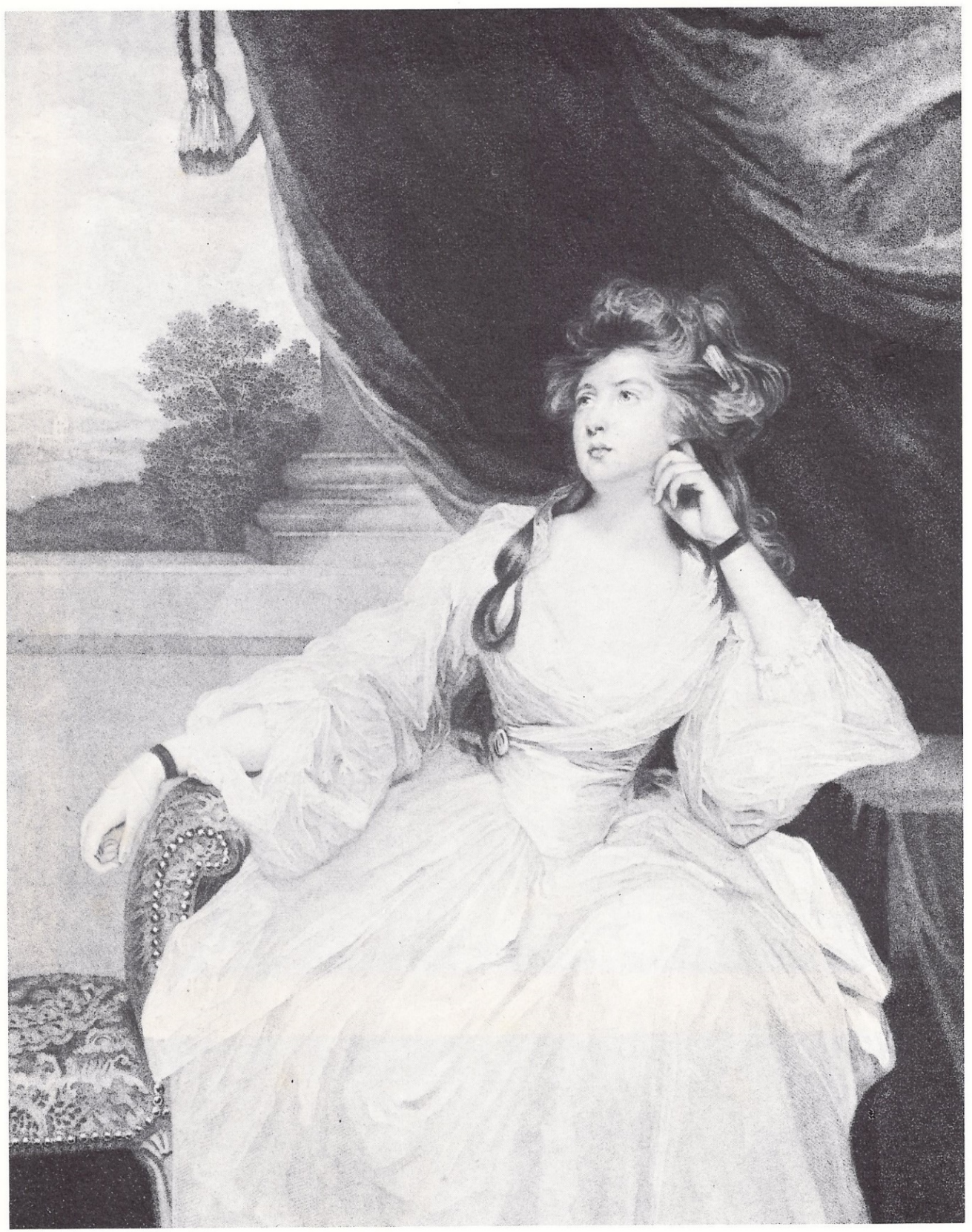

Reynolds: The Hon. Mrs Stanhope as Contemplation. Engraving by Caroline Watson. London, British Museum 


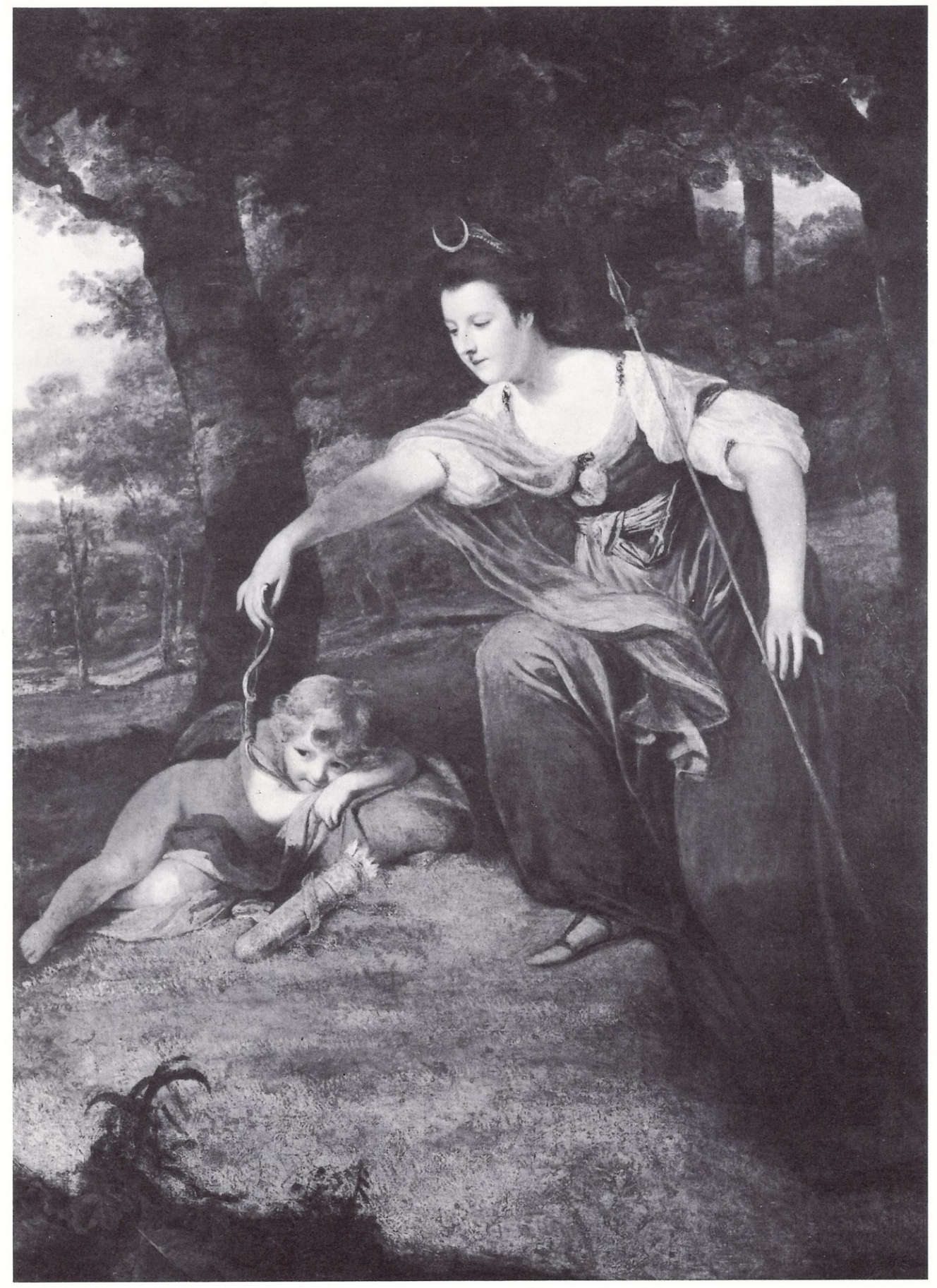

Reynolds: Elizabeth, Duchess of Manchester, as Diana with her son George, Viscount Mandeville, as Cupid. Wimpole Hall, The National Trust 


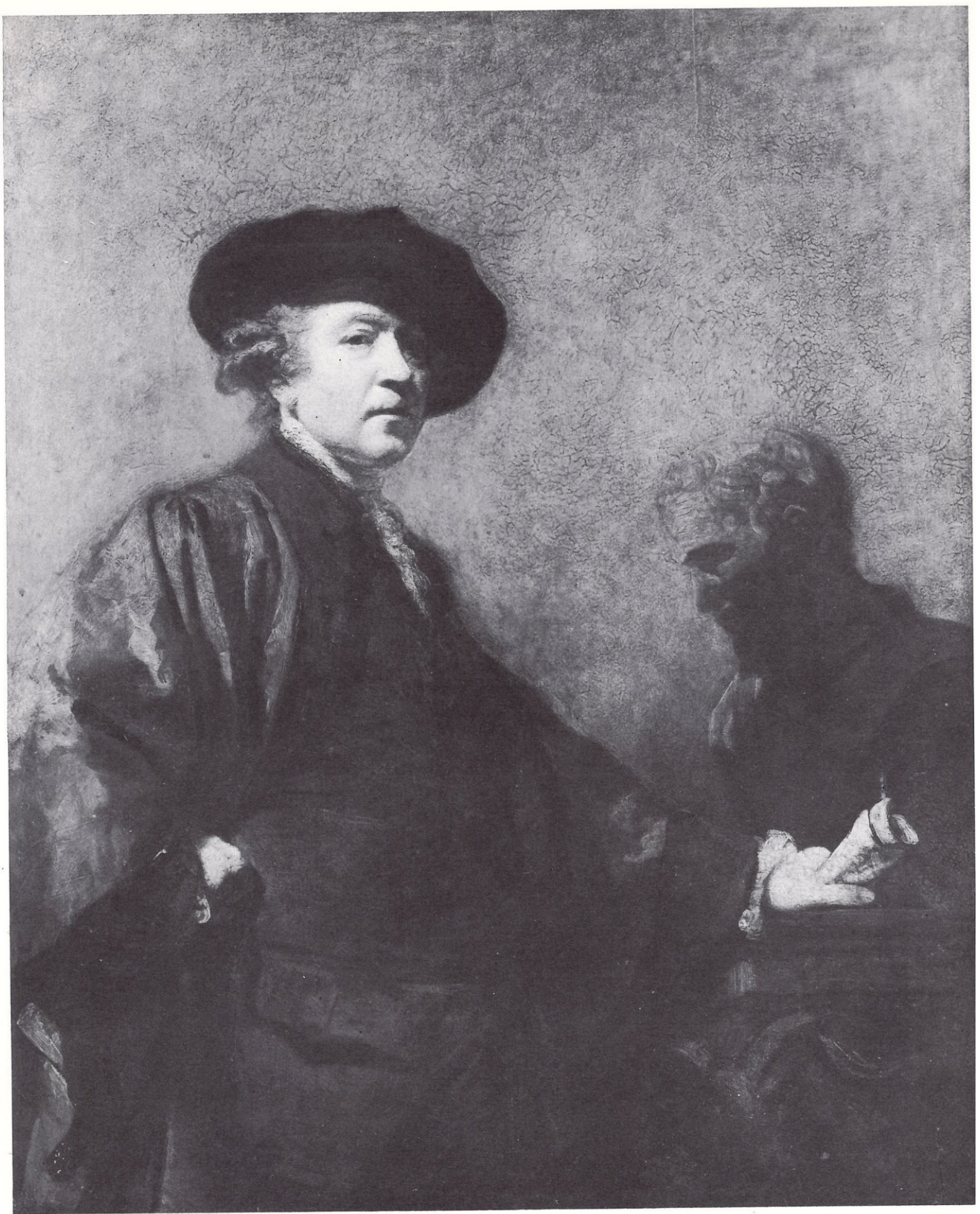

Reynolds: Self-portrait with a bust of Michelangelo. London, The Royal Academy of Arts 